\title{
Regeneration of Raw Hide Water Balance by Electrochemically Activated Water

\author{
by
}

\author{
A. Danylkovych, ${ }^{a}$ O. Korotych, ${ }^{b, 1^{*}}$ and O. Romaniuk ${ }^{c}$ \\ ${ }^{a}$ Department of Biotechnology, Leather and Fur, Kyiv National University of Technologies and Design \\ 2 Nemyrovych-Danchenko St, Kyiv 01011, Ukraine \\ ${ }^{b}$ Department of Chemical Engineering, University of Florida, 1030 Center Dr, Gainesville, FL 32611, USA \\ ${ }^{'}$ Department of Heat Power Engineering, Resource-Saving and Technogenic Safety \\ Kyiv National University of Technologies and Design, 2 Nemyrovych-Danchenko St, Kyiv 01011, Ukraine
}

\begin{abstract}
Improving the collagen structure, which was impacted by the curing process, increases the efficiency of all subsequent structural transformations during leather production and results in the formation of a high-quality leather material. Herein, we studied the process of soaking green-salted horsehides in electrochemically activated aqueous solutions and the properties of resulting chrometanned leather. It was found that the process of soaking horsehides can be effectively carried out using an electrochemically activated solution (ECAS) - a mixture of catholyte and anolyte at a volume ratio of $5: 1$. Using this soaking solution, sodium sulfide (an environmentally harmful reagent), sodium carbonate, and detergent can be completely excluded from the technological solution. The use of ECAS at the soaking stage effectively regenerates the water balance of horsehides while maintaining a stable $\mathrm{pH}$ during the soaking process and increases the efficacy of liming and all subsequent processes. Considering the prominent structural differences (density and thickness) between the front and shell of horsehide, the developed method, which utilize ECAS for soaking, allows the entire process to be carried out on uncut horse hides instead of processing two parts separately, which is normally required. The chrome-tanned leather produced by the developed method in semi-industrial conditions has elastic-plastic properties which are superior compared to the leather produced by current technology. The developed method also results in increasing the area yield by $2.5 \%$. The resulting elastic leather can be used for manufacturing a variety of articles, including clothing, accessories, and footwear.
\end{abstract}

\section{Introduction}

The development of innovative technologies to produce leather materials involves implementing effective ways to carry out a variety of chemocolloidal reactions during the processing of natural raw materials. Improving the structure of raw hides, particularly after the curing process during preparatory stages, increases the efficacy of all subsequent structural transformations and the formation of a high-quality final leather material. The use of aqueous solutions with novel chemical compositions can minimize the process length which is necessary to protect natural raw materials from biological damage by microorganisms, especially in the beginning of the hide processing. ${ }^{1}$ These solutions should be also scalable and inexpensive considering the significant volumes which are used during multistage processing of raw hides.

Activated aqueous solutions can be used as new alternatives to technological solutions during the processing of raw hides. To produce the activated aqueous solutions, different methods, such as ultrasonic or electric fields, can be used. ${ }^{2,3}$ Treatment of animal hides and skins with activated solutions has a number of advantages over other varieties of water treatments which utilize traditional technological solutions. ${ }^{3-5}$ Particularly, activated solutions maintain their properties, nonequilibrium thermodynamic state and high oxidation-reduction potentials (ORP), for a prolong time. These properties contribute to the intensification of biotechnological processes.

Among activated solutions, electrochemically activated (ECA) solutions have a potential role as disinfectants in medicine and industry due to their biocidal properties, in situ generation from inexpensive materials (water and salts such as $\mathrm{NaCl}$ ), and environmental compatibility (refer to the review ${ }^{6}$ ). ECA solutions, also denoted as electrolyzed oxidizing (EO) water, mixed oxidant (MIOX) solutions, and electrochemically activated water (ECAW), are produced by electrolysis of dilute salt solutions in an electrolytic cell where the cathode and anode are separated by a membrane. Electrochemical activation of water yields two fractions, catholyte and anolyte, with highly specific physicochemical properties regarding $\mathrm{pH}$, ORP, electroconductivity, and the presence of chemically active radicals and ions. The main reactions that occur during electroactivation of aqueous sodium chloride solutions can be summarized as:

\begin{tabular}{c|c} 
anode: & cathode: \\
\hline $2 \mathrm{H}_{2} \mathrm{O}-4 e^{-} \rightarrow \mathrm{O}_{2} \uparrow+4 \mathrm{H}^{+}$ & $2 \mathrm{H}_{2} \mathrm{O}+2 e^{-} \rightarrow \mathrm{H}_{2} \uparrow+2 \mathrm{HO}^{-}$ \\
$2 \mathrm{Cl}^{-}-2 e^{-} \rightarrow \mathrm{Cl}_{2} \uparrow$ &
\end{tabular}

* corresponding author: o.i.korotych@gmail.com

Manuscript received April 10, 2020, accepted for publication May 12, 2020. 
Depending on the operating parameters of electrolytic cell, the resulting anolyte solution will have a high ORP (oxidizing), a low $\mathrm{pH}$ (which can be neutralized by reconfiguring the electrolytic cell), and a variable concentration and type of chlorine-containing moieties. The catholyte will be characterized by low ORP (reducing) and a high $\mathrm{pH}$. Catholyte and anolyte can be also combined in a specific proportion to achieve desirable properties of electroactivated solution. The relative volumes of catholyte and anolyte in a given solution will determine its final $\mathrm{pH}$.

As an alternative to chlorine forms and other oxidants, ECA solutions also contain a mixture of reactive oxygen species and free radicals. Higher organisms possess antioxidant defense systems, whereas microorganisms generally do not. The presence of the free radicals, with their high oxidizing effects, in the solutions are considered of great importance to effectively destroy a wide variety of microorganisms. The active antimicrobial components of ECA solutions have been reported to include $\mathrm{HOCl}$, hydroxyl radical, and other short-lived oxidative moieties like $\mathrm{ClO}_{2}$.

Based on many reports, it has been shown that anolyte solutions have a broad spectrum of antimicrobial activity ${ }^{6-17}$ while catholyte solutions are characterized by their cleaning properties, including biofilm removal..$^{10,12,16-19}$ In addition to antibacterial and sporicidal activity ${ }^{6,20,21}$ ECA solutions have antiviral and fungicidal activities ${ }^{6,22}$ and inactivate toxins ${ }^{6}$ while maintaining high biocompatibility ${ }^{23}$ and antioxidative properties. ${ }^{24,25}$

ECA solutions have been used in many different areas, ${ }^{6}$ specifically for (i) the treatment and prevention of wound infection and periodontal diseases; (ii) medical device disinfection, including dental unit water lines, ${ }^{10}$ which if inadequately disinfected, may harbor polymicrobial biofilms containing potentially pathogenic organisms; and (iii) for disinfection of surfaces ${ }^{12}$ and food products $^{26-28}$ which may help to control infection outbreaks.

Authors of the work $^{14}$ assessed the performance of sodium hypochlorite $(\mathrm{NaOCl})$ and ECA water in terms of disinfection efficacy, disinfection by-products formation and the stability of the disinfectant with respect to storage. ${ }^{14}$ In the absence of or at low concentrations of dissolved organic carbon, ECA solution showed better disinfection efficacy in terms of Escherichia coli inactivation at both $\mathrm{pH} 5$ and 7 while forming fewer by-products. Also, ECA solution was more stable during storage compared with $\mathrm{NaOCl}$ solution. Acidic ECA solution retains useful bactericidal activity for more than 12 months, which can significantly expand its potential applications..$^{22}$ During the recovery of ECA solution, the chemical components of the solution will shift spontaneously from their thermodynamically unequilibrated conditions to a stable nonactive form. Thus, ECA solution will slowly revert to a dilute salt solution without presenting any environmental hazards. Moreover, ECA solutions can be effectively inactivated by organic matter and are considered as "green biocides" which can help to reduce the consumption of free chlorine and replace other toxic chemicals. ${ }^{22}$

Many industrial processes can benefit from utilizing ECA solutions. For example, the high potential of catholyte as an environmentally friendly alternative to laundry detergents for sustainable consumption of cotton textiles have been described. ${ }^{18}$ In addition to its cleaning properties, catholyte also exhibits a plasticization effect on the collagen structure of the dermis of leather materials which results in reduced stress at the final stage of product formation during footwear manufacturing. ${ }^{29}$ As a result of the catholyte treatment of the leather part of fur and leather, the plasticity of the materials has been restored. ${ }^{30,31}$

Experimentally, the use of both catholyte and anolyte in the processing of raw fur materials was reported previously. ${ }^{32}$ The anolyte was effectively used in the process of restoring the collagen structure of the raw material and releasing inter-fiber proteins, polysaccharides and partially lipids. ${ }^{32}$ Owing to anolyte bactericidal properties it was possible to carry out the process without adding antiseptic substances. At the second stage of soaking and degreasing the raw biomaterial, catholyte was used to remove the remaining lipids. The use of ECA solutions resulted in decreasing the time required to process fur materials without the application of toxic reagents. ${ }^{33}$

Thus, the results of the aforementioned studies specify the particular physicochemical, cleaning and antiseptic properties of the ECA solutions, especially, for processing plant and animal raw materials. This can indicate their promising application for the improvement and development of innovative methods for producing leather and fur. Utilizing solutions with a broad spectrum of antimicrobial activity at the preparatory stages becomes especially highly important after a new kind of bacterial defect on hides/skins and leather has been identified as a microbial biofilm which differs from the previously well-known bacteria-borne defects such as hair slip, red discoloration, and grain pilling. ${ }^{1}$

Thus, the goal of this work was to study the process of soaking greensalted horsehide using electrochemically activated solutions. To achieve this goal, the following tasks were defined:

- to determine the effect of various fractions of electrochemically activated water on the kinetics of water absorption by different areas (cuts) of horsehide;

- to establish the relationship between water sorption by horsehide and $\mathrm{pH}$ of the solutions used during the soaking;

- to determine the effect of the soaking process on the chemical composition and properties of the chrome-tanned leather which was produced by the developed method including soaking in electrochemically activated aqueous solutions in the semiindustrial conditions. 


\section{Materials and Methods}

Leather, as a natural material, can differ significantly in properties not only between different types of hides and skins but also between its different regions. ${ }^{34}$ The difference in properties between various regions is the most prominent for horsehides, yet the information on the tear strength variability and collagen fibril orientation together with other properties across horsehide are very scarce.

In this study, the green-salted horse raw hide with the thickness and initial moisture content in the areas of the horsefront and shell (Fig. 1) equal to $2.2-2.7 \mathrm{~mm}$ and $47.8 \%$ and $4.8-5.9 \mathrm{~mm}$ and $44.1 \%$, respectively, were used.

\section{Laboratory Testing}

After raw hide fleshing and mechanical removal of its pelage and before soaking, three samples (approx. $100 \mathrm{~g}$ each) were cut out from the horsehides and washed with water (50\% excess of the total sample mass) for an hour at $26-28^{\circ} \mathrm{C}$. Washing and soaking were carried out at a rotational speed of $15-17 \mathrm{rpm}$ (in a vertical plane) using custom-made laboratory equipment shown in Fig. 2.

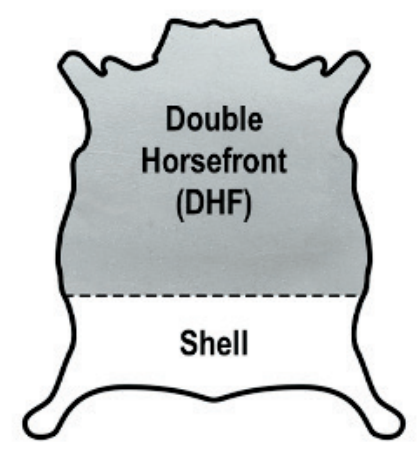

Figure 1. Standard horsehide leather cuts: front and shell.

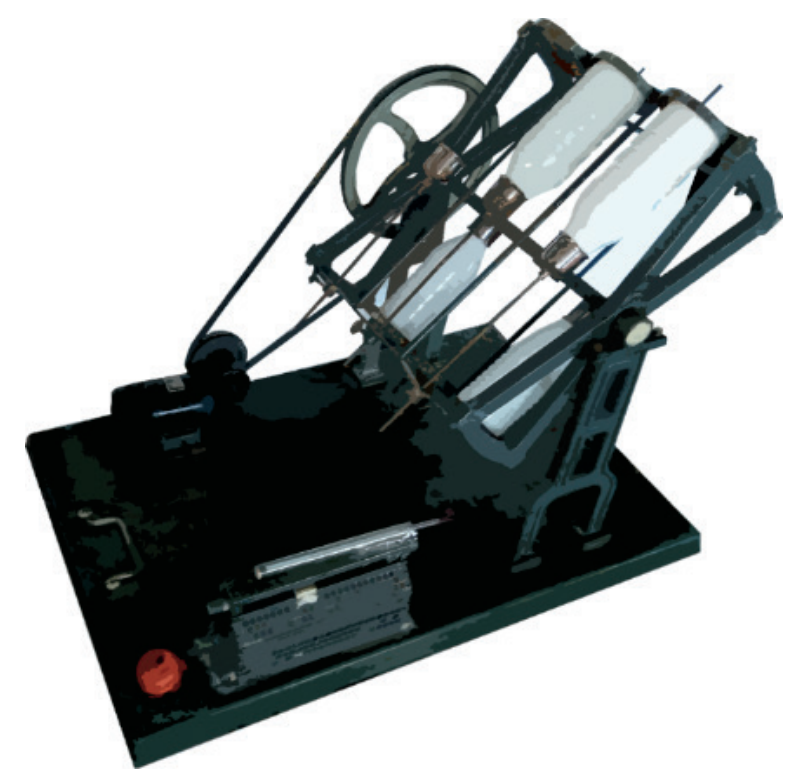

Figure 2. Photo of custom-made laboratory equipment used for washing and soaking of horsehide samples.
Fractions of ECA water - anolyte and catholyte with a $\mathrm{pH} 3.3$ and 10.3 , respectively, were produced by electrolysis of $5 \mathrm{mM} \mathrm{NaCl}$ solution in an electrolytic cell (Ekovod, technical specifications: TU y29.1-1285006876.001-2000) with a silicon anode, a steel cathode, and an ion-exchange cotton membrane ${ }^{35,36}$. For the regeneration of water balance which was affected during the curing process and transportation, horsehide soaking in solutions based on ECA water was studied. Particularly, catholyte, catholyte supplemented with $\mathrm{Na}_{2} \mathrm{~S}(2 \mathrm{~g} / \mathrm{L})$ and 5:1 catholyte-anolyte mixture was used to study the kinetics of water absorption. For controls, distilled water and industrial soaking solution ${ }^{37}$ containing non-ionic surface-active substance SPK-50 (0.25\% of the sample mass, technical specifications: TU 2484-014-22284995-99), sodium carbonate (0.45\% of the sample mass) and sodium sulfide ( $0.30 \%$ of the sample mass) were used.

The $\mathrm{pH}$ of the soaking solutions was measured with a $\mathrm{pH}$ meter (Gomel Plant of Measuring Devices, pH-340), while water content of the samples was determined gravimetrically.

For water absorption studies three samples per group were cut from the right and left half-skins of cured raw hides after their fleshing in the form of symmetrical strips close to the line separating front and shell. After removing the hair with a razor blade knife, the samples were weighed on scales (AXIS, AD200). After all the samples were washed simultaneously, they were carefully but thoroughly dried with filter paper to remove the excess surface water and weighed again. This procedure was repeated after 2, 4, 7, $17 \mathrm{~h}$ (Fig. 3) and 1, 3, 6, $16 \mathrm{~h}$ (Fig. 4). The water content in the samples was calculated according to the following formula:

$$
W A=\frac{\left(m_{1}-m_{2}\right)}{m_{2}} 100 \%
$$

where WA - water absorbed by the sample [\%]; $m_{1}$ and $m_{2}-$ the sample weight before and after drying [g]. To determine the dry weight after measurements the samples (2-2.5 g) were dried at $102 \pm 2{ }^{\circ} \mathrm{C}$ for $4 \mathrm{~h}$, equilibrated for $30 \mathrm{~min}$ in a desiccator at room temperature and weighed.

\section{Semi-Industrial Testing}

After laboratory experiments, the horse hides were processed in semi-industrial conditions using the developed method and the current technology as a control. In the developed method a slightly alkaline ECA solution obtained by mixing catholyte and anolyte fractions at volume ratio $5: 1$ was used for soaking. In the developed method the soaking process was carried out using three halves $(\sim 1.2$ $\mathrm{m}^{2}$ each) of hides along the back bone line, while according to the current technology the horsefront and shell were processed separately yielding, respectively, elastic and boardy leather materials (Fig. 6).

For removal of the epidermis and hair from the horse pelts, the raw hide was further subjected to liming using a mixture of calcium hydroxide ( $4 \%$ of the sample mass) and sodium sulfide ( $3 \%$ of the 
sample mass). The processing of horse raw hides was carried out in a revolving drum (Dose, $0.39 \mathrm{~m}^{3}$ ) at a private joint-stock company "Chinbar" (Kyiv, Ukraine). Further processing of the limed hides, including deliming, pickling, tanning, shaving, neutralizing, tanning with chromium salts and plant extracts, fat-liquoring, samming, setting out and final drying were performed according to the previously described technology. ${ }^{37}$ Briefly, the horsehide after tanning with chromium (III) compounds (technical specifications: TU 2141-033-54138686-2003) was skived to a uniform thickness of 1.4-1.5 mm; post-tanned with chromium (III) compounds in the amount of $2 \%$ of the hide mass; neutralized with a mixture of sodium formate and sodium bicarbonate with a weight ratio of $4: 1$; filled with organic compounds: acrylic polymer Retanal RCN-40 (Cromogenia Units SA, $4 \%$ of the hide mass) and quebracho (5\% of the hide mass); and fat-liquored with Trupol RA (Trumpler, $8 \%$ of the hide weight mass). The filling-fat-liquoring process was completed after fixation of reagents in the structure of re-tanned hides with $10 \%$ formic acid at $\mathrm{pH}$ 4.2. After the drying-moisturizing processes, ${ }^{38}$ the samples of the resulting semi-finished leather were set out.

\section{Physicochemical Characterization}

The chemical composition and physicomechanical properties of the leather samples were determined by the methods described in our previous work ${ }^{39}$ after conditioning at $20 \pm 2^{\circ} \mathrm{C}$ and $65 \pm 5 \%$ relative humidity of the air (ASTM D1610-18). Briefly, the total ash was determined thermogravimetrically after oxidizing the sample $(7.5 \mathrm{~g})$ in air at $600 \pm 25^{\circ} \mathrm{C}$ until constant mass was reached (ASTM D261717a and GOST 938.2-67). The weighed residual matter, termed "ash", was calculated as a percentage from the original sample. Liquid pycnometry was utilized to measure the apparent density of the samples $(10 \mathrm{~g})$ at $22^{\circ} \mathrm{C}$ using kerosene as a solvent. Considering that collagen is the primary structural element in the extracellular matrix in animal hides/skins, the heat resistance of leather against shrinkage was characterized by the hydrothermal denaturation or shrinkage temperature $\left(\mathrm{T}_{\mathrm{S}}\right)$ of collagen molecules ${ }^{40}$ by gradually heating the sample in a mixture of glycerol and water with a $4: 1$ weight ratio at the heating rate of $2-3^{\circ} \mathrm{C} / \mathrm{min}$ (ASTM D6076-18 and DSTU 272694). Before the measurements, the samples were thoroughly soaked in water for $4 \mathrm{~h}$ at $20 \pm 1^{\circ} \mathrm{C}$. Chromium content was determined by iodometric titration and expressed as the mass fraction of chromium (III) oxide. Mechanical properties (tensile stress and elongation) were measured using a tensile testing machine (PM-250M) at extension rate $90 \mathrm{~mm} / \mathrm{min}$. Initial length of $10 \mathrm{~mm}$ wide leather samples between clamps was $50 \mathrm{~mm}$. Content of the bound organic tannins (BOT) [\%] in the leather samples was calculated using the following formula: $\omega_{B O T}=\omega_{L}-\omega_{N}$, where $\omega_{L}=100-\left(\omega_{T A}+\omega_{O S}+\omega_{O W S}\right)-$ the mass fraction of leather substances calculated on the dry basis [\%]; $\omega_{T A}$ - the mass fraction of total ash [\%]; $\omega_{O S}$ - the mass fraction of organic substances (OS), unbound fatty acids, extracted with organic solvents (GOST 938.5-68) [\%]; $\omega_{\text {OWS }}$ - the mass fraction of organic water-soluble substances (OWS) (GOST 938.6-68) [\%]; $\omega_{N}-$ the mass fraction of nitrogen-containing water extractable materials (determined according to the previously described methodology, ${ }^{38}$
ASTM D6016 - 17) [\%]. The content of substances extracted with organic solvents was determined using a Zaivhenko extraction apparatus. A crushed sample (5 g) within a paper shell was put into the extractor and solvent extraction with tetrachloromethane was carried out for $1.5 \mathrm{~h}$. After solvent evaporation under vacuum, the fatty substances were dried in an oven at $128-130^{\circ} \mathrm{C}$ for $1 \mathrm{~h}$. After cooling the flask in the desiccator, the flask with unbound fatty acids was weighed and the mass fraction of OS was calculated. To calculate the yield, the surface area of leather was determined using specialized electromechanical machinery (Svit, model 07484/P1).

\section{Result and Discussion}

\section{Structure and Composition of Raw Hides}

Collagen is the main and the most abundant structural protein in the extracellular matrix of various animal tissues, including skin, bone and tendon. The fibrous collagen provides tensile strength, while glycosaminoglycans (GAGs), covalently linked to proteins to form proteoglycans, act as space-fillers and provide resistance to compression. ${ }^{41}$ Skin components such as keratin, albumins, and globulins together with GAGs (e.g., hyaluronic acid), proteoglycans (e.g., dermatan sulfate), triglycerides and lipids are usually removed during the earlier stages of hide and skin processing..$^{42}$ Removal of these non-collagenous proteins is a necessary step to produce soft leather material as it allows the collagen fiber structure to split apart. This "opening up" effect results in a successful implementation of all subsequent structural transformations.

Many varieties of collagen have been identified; for example, mammals have about 20 different genes which code various forms of collagen. ${ }^{41}$ As a function of structure and supramolecular organization, collagen can be classified as fibril-forming (types I, II, III, V, and XI), fibril-associated (types IX, XII, and XIV), or network-forming (types IV, VII, VIII, and X). ${ }^{43}$ Tropocollagen, a collagen molecule, being a right-handed triple helix stabilized mostly by hydrogen bonding is the major structural element of collagen. Heterotrimers of two a1(I) and one a2(I) protein chains which only slightly differ in amino acid sequence are the dominant isoform of type I collagen. The polypeptide chains contain glycine at every third position and have a high proline and hydroxyproline content. ${ }^{41,42}$ All collagen molecules in a precursor form, called procollagen, are synthesized intracellularly by connective-tissue cells and then secreted by exocytosis. Additional peptide extensions at each end of procollagen hinder premature assembly of collagen molecules. Extracellular enzymes, procollagen proteinases, cut off these terminal extensions to allow collagen assembly only after the molecules have been extracted. At each end of the helical region of the procollagen molecule, there is a non-helical region known as telopeptide. Collagen, being a multi-hierarchical structure, is organized in four levels of macromolecular structure: first the collagen molecules pack together into collagen fibrils, then the fibrils are further organized into larger fibril bundles, then they are arranged into fascicles and finally - into fiber bundles. 


\section{Water Absorption by Horsehide}

The chemical treatments and mechanical processes used to produce leather from hides and skins result in structural changes in collagen fibrils and their supramolecular organization. ${ }^{44}$ Even though the general chemistry used in hide and skin processing is well-known, the structural changes at the level of the collagen fibrils is just starting to be revealed utilizing $x$-ray scattering techniques. ${ }^{45-47}$ Herein we focused on the macroscopic effect of the composition of the soaking solutions on water sorption by horsehide and the correlations with the properties of corresponding final leather material.

Generally the water sorption of collagen and other fibrous proteins in acidic and alkaline solutions is predominantly governed by the osmotic pressure difference arising between the protein phase and the external solution and by protein cohesion. ${ }^{48}$ According to the literature data, the isoelectric point of collagen, which can be affected by the nature and ionic strength of the salts presented in the solution, is 4.7 , although a second critical point in the collagen behavior has frequently been noted at $\mathrm{pH} 7.7 .^{49}$ The maximum equilibrium swelling is usually observed at an external $\mathrm{pH}$ between $2-3$ and 11-12, while the minimum - at the isoelectric point. ${ }^{50}$

The kinetics of water absorption by green-salted horsehide was determined for technological solutions with different compositions (Fig. 3 and Fig. 4). It should be noted that the soaking process of the raw hide was carried out after washing the salt off the samples. To estimate the sorption of ECA solution by the dermis, the soaking process was also carried out using distilled water as an additional control (Fig. 4).

As it can be seen from the data, after rapid solution uptake within the first $3 \mathrm{~h}$, a further increase in water content, which was not complete after 16-17 h, was observed. The results also indicate that solution

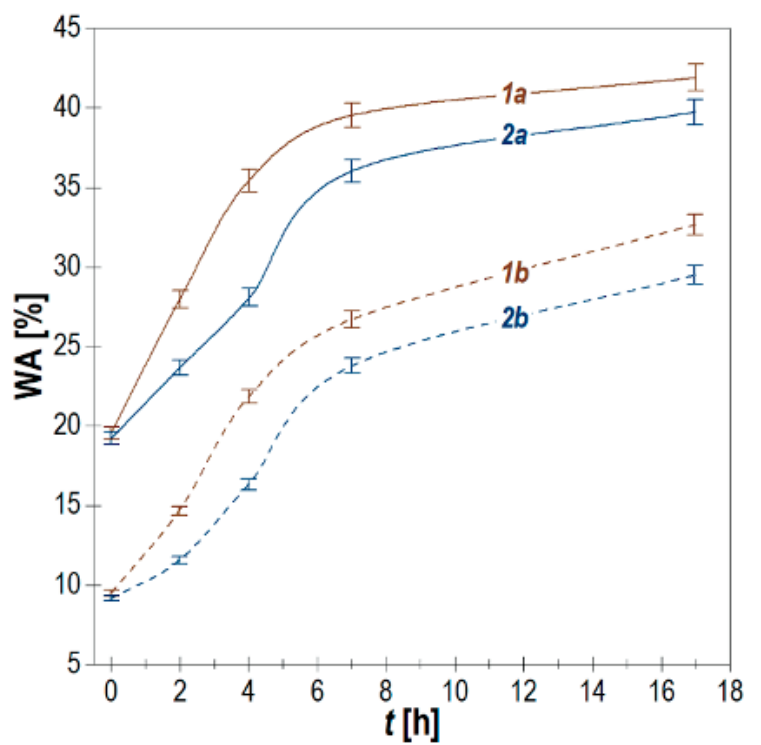

Figure 3. Kinetics of water absorption (WA) by the dermis of horsehide in a $5: 1$ mixture of catholyte and anolyte (1) and in a control soaking solution according to the existing technology (2) for horsefront (a, solid lines) and shell (b, dash lines).

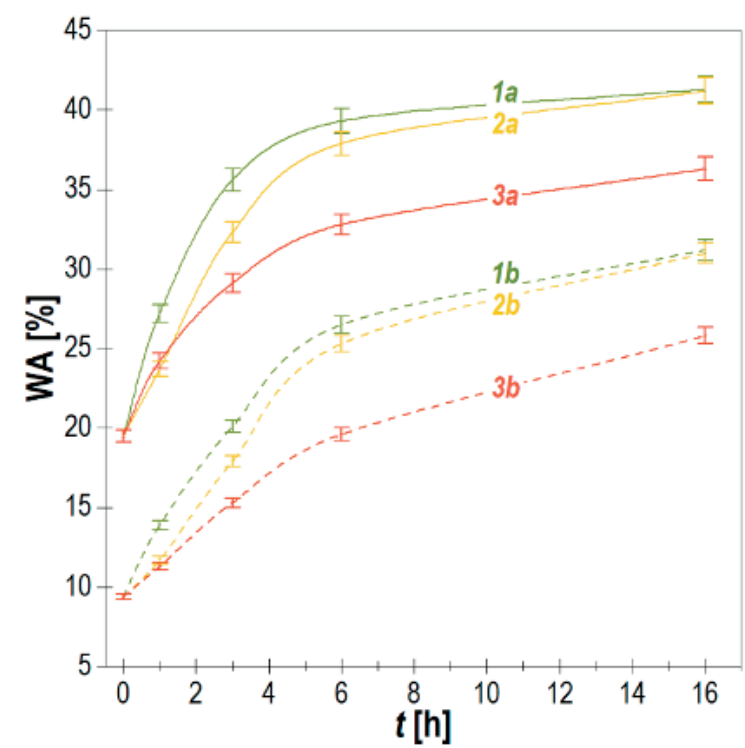

Figure 4. Kinetics of water absorption (WA) by the dermis of horsehide in catholyte (1), catholyte supplemented with $\mathrm{Na}^{2} \mathrm{~S}$ (2), and distilled water (3) for horsefront (a, solid lines) and shell (b, dash lines).

composition significantly affects the kinetics of water absorption and the final water content in the samples. The most prominent effect was observed for the sample soaked in the mixture of catholyte and anolyte with a $5: 1$ volume ratio (Fig. 3) and catholyte (Fig. 4). This is manifested by faster water absorption, especially in the beginning of the soaking, and a higher water content after $17 \mathrm{~h}$ of soaking compared to the control group (existing technology). After the first hour of soaking, the horsefront absorbs twice as much water as the shell. Additionally, the $\mathrm{pH}$ of the solution is reduced to a greater extent for the control group $(\Delta \mathrm{pH}=3.4)$ and for catholyte group $(\Delta \mathrm{pH}=3.1)$ compared with the mixture of catholyte and anolyte for which the $\mathrm{pH}$ difference was 1.1 (Fig. 5).

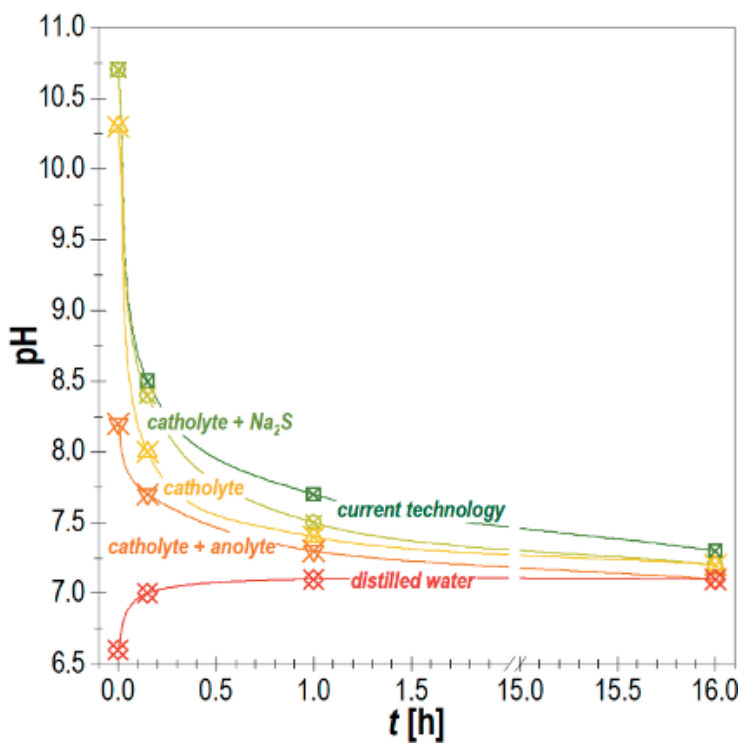

Figure 5. Change in the $\mathrm{pH}$ of technological solutions during soaking of horse raw hide. 
The water sorption by horse raw hides is sensitive to the solution $\mathrm{pH}$ and its composition and increases with increasing $\mathrm{pH}$ until it reaches a maximum at 8.2 (Fig. 4 and Fig. 5). At $\mathrm{pH}$ lower than 8.2 the water content is decreased, while at higher $\mathrm{pH}$ it remains almost the same for horsefront or decreases for shell. The effect of solution composition can be seen comparing the kinetics of swelling horsehide in catholyte supplemented with $\mathrm{Na}_{2} \mathrm{~S}$ and in control soaking solution. Even though the initial $\mathrm{pH}$ of the solution is the same, the water sorption rate and the water content is lower for the samples swollen in the latter solution.

The water sorption by horsehides, in addition to hydration of hydrophilic groups of macromolecules, can be explained by the local change in the protonation degree of carboxyl groups of collagen, GAGs/proteoglycans, and other macromolecules in the beginning of the soaking. ${ }^{51}$ The observed decrease in $\mathrm{pH}$ within the first few hours (Fig. 5) can be explained by the neutralization of hydroxyl anions presented in the solutions by protons which were released during dissociation of carboxyl groups. The electrostatic repulsion between negatively charged carboxylate groups and an increased ion concentration inside the dermis due to ionization will result in an increase in osmotic pressure which can cause the observed increase in the water content. In addition to the increased osmotic pressure, the increased mobility of the collagen macromolecules due to the disruption of some of its physical and chemical crosslinks and removing (washing out) of non-collagenous components of the dermis can also contribute to the increased water content. Furthermore, negatively charged polysaccharide chains of GAGs even at low concentrations can form hydrophilic gels: their multiple negative charges at carboxyl groups attract cations, such as $\mathrm{Na}^{+}$, that are osmotically active, causing large amounts of water to be absorbed by the sample. This gives rise to a swelling pressure, which is balanced by tension in the collagen fibers interwoven with the proteoglycans. ${ }^{41}$

During the soaking process using an industrial soaking solution, uneven hydration (blistering), caused by the lower density of the outer layers and faster water absorption of alkaline solution ( $\mathrm{pH}$ 10.7) which results almost in complete ionization of carboxyl groups, was observed. A similar effect of water absorption by the skin dermis was also found for the samples soaked in alkaline solutions of catholyte with and without sodium sulfide with $\mathrm{pH} 10.3$ and 10.7, respectively. A uniform hydration, probably due to less rapid $\mathrm{pH}$ change and more effective and homogeneous water absorption by the whole dermis using catholyte and anolyte mixture can indicate deeper changes in the structure of the dermis on the microfibrillar level.

Generally, faster kinetics of water absorption was observed for the horsehides soaked in electroactivated solutions (Fig. 3 and Fig. 4). This effect can be explained by the declasterization of the water structure after its activation and additional changes in the water structure and water/macromolecule interactions in the presence of ions and free radicals. ${ }^{32}$

Thus, among tested soaking solutions, the catholyte and anolyte mixture provides uniform swelling without blistering and more effective regeneration of water balance of raw leather material while maintaining a stable $\mathrm{pH}$ during the soaking process. Higher water content in the horsefront and shell samples soaked in a mixture of catholyte and anolyte and a smaller difference between them compared with the control group (Fig. 3) indicates the possibility of simultaneous processing of the whole hide rather than processing the two parts separately (i.e., horsefront and shell).

Thus, in slightly alkaline solutions with moderate salt concentration (to avoid electrostatic screening and corresponding decrease in hydration) the water sorption will depend on solution solubilizing efficacy and its ability to decrease the collagen crosslinking degree.

The higher content of organic substances extracted from the raw material after soaking in ECA solution (Table I) compared with the control group (industrial soaking solution) also indicates more effective interaction of the activated water with the components of the dermis. This effect is more pronounced for the samples from shell which contains more soluble proteins and GAGs than the horsefront. Despite increased density of shell samples compared to the horsefront samples, 5.6\% more organic substances were extracted from the former samples. It should be noted that the process of

Table I

Content of inorganic and organic substances in solutions after soaking of horsehide, apparent density, and hydrothermal stability.

\begin{tabular}{ccccccc}
\hline \multirow{2}{*}{$\begin{array}{c}\text { Horsehide } \\
\text { leather cut }\end{array}$} & Solution & \multicolumn{2}{c}{ Mass fraction of substances [\%] } & & \\
\cline { 3 - 4 } & \multirow{2}{*}{ Horsefront } & Inorganic & Organic & Density $\left[\mathbf{g} / \mathbf{c m}^{3}\right]$ & $T_{S}\left[{ }^{\circ} \mathbf{C}\right]$ \\
\hline \multirow{2}{*}{ Shell } & catholyte + anolyte & $14.4 \pm 0.3$ & $85.6 \pm 1.7$ & & $1.18 \pm 0.04$ & $64.0 \pm 0.6$ \\
& control & $15.4 \pm 0.3$ & $84.6 \pm 1.7$ & $1.18 \pm 0.04$ & $63.0 \pm 0.6$ \\
\hline \multirow{2}{*}{ catholyte + anolyte } & $13.4 \pm 0.3$ & $86.6 \pm 1.7$ & $1.24 \pm 0.04$ & $62.0 \pm 0.6$ \\
& control & $18.2 \pm 0.4$ & $81.1 \pm 1.6$ & $1.21 \pm 0.04$ & $63.0 \pm 0.6$ \\
\hline
\end{tabular}


soaking the shell samples in activated solutions is accompanied by significant foam formation indirectly indicating the extraction of GAGs along with other water-soluble proteins.

Based on the results, soaking the horsehide in solutions of ECA water results in a higher efficacy of carrying out this process using a mixture of catholyte and anolyte at a volume ratio of $5: 1$ with $\mathrm{pH}$ 8.2. This eliminates the need to use the environmentally harmful sodium sulfide for soaking and facilitates the process with a smaller change in $\mathrm{pH}$ at the initial soaking stage. Higher water content and less variation in water content between the horsefront and the shell after soaking using a mixture of catholyte and anolyte compared with the control indicate the possibility of carrying out the entire technological cycle of manufacturing leather from green-salted raw hide using the whole horsehide.

\section{Properties of the Horse Leather Produced} in Semi-Industrial Conditions

To test the developed method in the semi-industrial conditions, the three half-skins from green-salted horse hides were used. The differences between developed method and current technology are summarized in Fig. 6.

The results of the liming process are shown in Table II and Table III. As it can be seen from the data, the pickled horsehide produced by the developed method contains $8.2 \%$ and $12.4 \%$ more inorganic substances for horsefront and shell areas compared with the existing technology. This indicates the profound structural changes in the soaked hides using ECA water, especially within the denser parts of raw hides - shell.

The properties of leather material are closely related to organization and supramolecular structure of collagen and results from the interplay of electrostatic, hydrophobic and van der Waals interactions in addition to hydrogen and covalent bonds..$^{43}$ During liming in a strongly alkaline environment further disruption of intra- and intermolecular bonds within fibrous collagen structure

\section{Table II}

Content of inorganic substances in the pickled horsehides processed in semi-industrial conditions.

\begin{tabular}{lcc}
\hline Technology /Method & Horsehide leather cut & Total ash [\%] \\
\hline \multirow{2}{*}{ Developed } & horsefront & $0.92 \pm 0.02$ \\
& shell & $1.18 \pm 0.02$ \\
Existing & horsefront & $0.85 \pm 0.02$ \\
& shell & $1.05 \pm 0.02$ \\
\hline
\end{tabular}

Table III

Properties of the pickled horsehides limed in semi-industrial conditions according to the existing technology.

\begin{tabular}{lcccc}
\hline \multirow{2}{*}{$\begin{array}{l}\text { Mechnology / } \\
\text { Method }\end{array}$} & \multicolumn{2}{c}{ Density $\left[\mathrm{g} / \mathrm{cm}^{3}\right]$} & \multicolumn{2}{c}{$T_{S}\left[{ }^{\circ} \mathrm{C}\right]$} \\
\cline { 2 - 5 } horsefront & shell & horsefront & shell \\
\hline Developed & $1.03 \pm 0.03$ & $1.12 \pm 0.03$ & $51.0 \pm 0.5$ & $57.5 \pm 0.6$ \\
Existing & $1.03 \pm 0.03$ & $1.12 \pm 0.03$ & $52.0 \pm 0.5$ & $59.0 \pm 0.6$ \\
\hline
\end{tabular}

and the formation of weakly dissociated salts of calcium hydroxide with carboxyl groups were observed. ${ }^{52}$ The hydrothermal stability of a leather material will reflect the stability of collagen structures at the molecular level and at several levels of supramolecular structure. $^{43}$ The shrinkage temperature of leather is affected by many different factors, most of which appear to alter the number and nature of crosslinks between adjacent polypeptide chains of the collagen protein macromolecules ${ }^{53-56}$. The value of the shrinkage temperature of leather is commonly used as an indicator of the type and degree of tannage or both. For both the developed and current method, this is testified by a decrease in the density after liming with a corresponding decrease in hydrothermal stability (Table III and Table IV). Based on shrinkage temperature, the pickled horse halfskins processed according to the developed method are structurally more "opened up" and prepared for the effective tanning-fatliquoring.

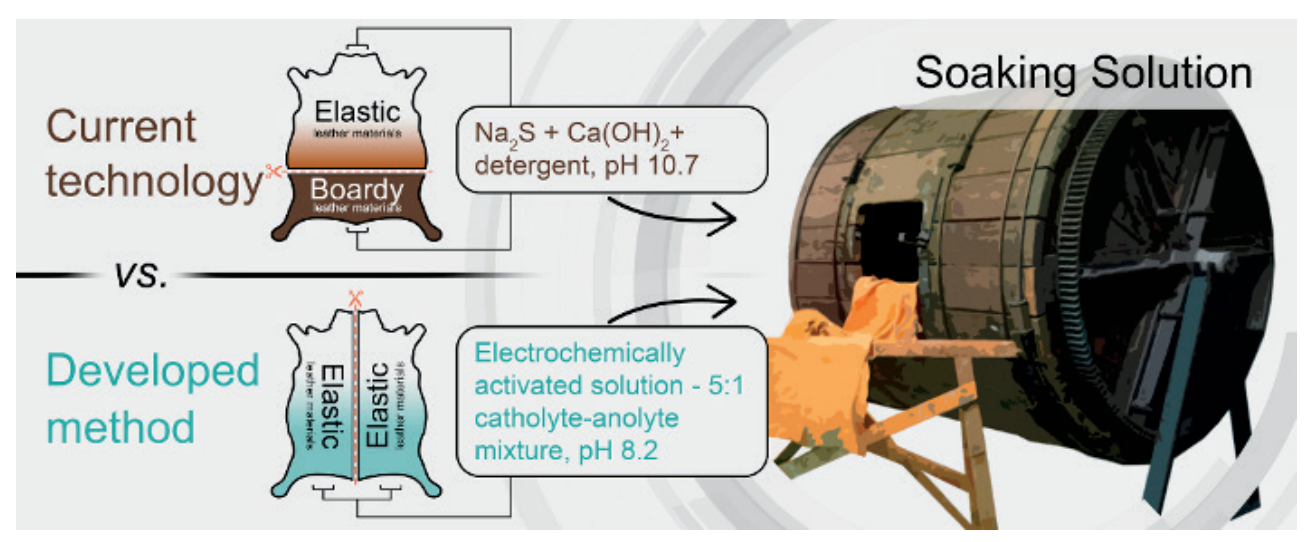

Figure 6. The differences in soaking stage between developed method and current technology during semi-industrial processing of horse raw hides. 
The half-skins processed by the developed method and current technology in semi-industrial conditions after drying-moisturizing treatments were analyzed based on their chemical composition and physicomechanical properties (Table IV). Comparative analysis of leather samples obtained according to the developed method indicates a higher content of tanning compounds of chromium and organic matter than those obtained by existing technology. At the same time, the amount of unbound fatty substances is $6 \%$ and $12 \%$ higher for areas of horsefront and shell processed using the developed method. These data correlate with the heat resistance of leather samples. The filled leather obtained according to the developed method is $2-3{ }^{\circ} \mathrm{C}$ more hydrothermally stable.

The increased content of fatty substances and uniform distribution within the structure of the leather obtained by the developed method will promote the mobility of the collagen fibrils under deformation. This statement is confirmed by the observed decrease in the density and increase in elastic-plastic properties of the leather material. This is especially true for the tensile strength and deformation of leather from the horsefront and shell areas. Both characteristics increase by 9-11\% (tensile strength) and 8-9\% (elongation before fracture).

Overall, the developed method utilizing ECA solution for soaking provides an efficient regeneration of water balance of horse raw hide and its further processing. This is also evidenced by an increase in the area to $0.4 \mathrm{~m}^{2}$ per $100 \mathrm{~kg}$ of raw hides. Based on the studied properties, the resulting leather can be used for manufacturing of clothing, accessories, and footwear.

\section{Conclusions}

It was established that the process of soaking of horse raw hides can be effectively carried out using the ECA solution - a mixture of catholyte and anolyte at a volume ratio of $5: 1$. The environmentally harmful reagent which is commonly used for leather soaking, such as sodium sulfide, together with sodium carbonate and surface-active substance(s) have been completely excluded from the composition of the soaking solution. Taking into account the peculiarities of the structure of horsehide, particularly, drastic difference in the thickness and the density of the horsefront and shell, an effective regeneration of water balance of the dermis takes place when a mixture of catholyte and anolyte is used to provide a stable $\mathrm{pH}$ environment during entire soaking process. The higher water content for the horsefront and shell samples during soaking and smaller difference between them compared to the samples processed using existing technology provide (1) the effective process of liming and (2) the basis for the processing of the whole horse raw hide at once into elastic leather. Soaking of green-salted horse raw hides in a mixture of catholyte and anolyte results in the formation of leather with the increased elastic-plastic properties and increase area yield by $2.5 \%$ compared with the existing technology which involves separate processing of the horsefront and shell. The leather made from the horse raw hides processed using the developed method meets the requirements of DSTU 3115-95 "Leather for garments - General specifications" and the international standard ISO 9001:2008 for "Quality management systems - requirements" and can be used for manufacturing of clothing, accessories and footwear.

Table IV

Characteristics of the filled leather.

\begin{tabular}{|c|c|c|}
\hline Characteristic & Developed method & Current technology \\
\hline \multicolumn{3}{|l|}{ - Mass fraction* $[\%]$} \\
\hline • chromium (III) oxide & $\frac{4.1 \pm 0.08}{3.6 \pm 0.08}$ & $\frac{3.8 \pm 0.08}{3.3 \pm 0.08}$ \\
\hline - substances extracted with organic solvents & $\frac{8.7 \pm 0.2}{6.6 \pm 0.1}$ & $\frac{8.2 \pm 0.2}{5.9 \pm 0.1}$ \\
\hline - bound organic tannings & $\frac{12.9 \pm 0.3}{8.7 \pm 0.2}$ & $\frac{12.2 \pm 0.2}{7.9 \pm 0.2}$ \\
\hline - Shrinkage temperature, $T_{s}\left[{ }^{\circ} \mathrm{C}\right]$ & $\frac{115 \pm 1}{111 \pm 1}$ & $\frac{113 \pm 1}{108 \pm 1}$ \\
\hline - Density $\left[\mathrm{g} / \mathrm{cm}^{3}\right]$ & $\frac{0.63 \pm 0.02}{0.66 \pm 0.02}$ & $\frac{0.65 \pm 0.02}{0.70 \pm 0.02}$ \\
\hline - Tensile strength $[\mathrm{MPa}]$ & $\frac{19.7 \pm 1.2}{22.6 \pm 1.4}$ & $\frac{17.7 \pm 1.1}{20.8 \pm 1.2}$ \\
\hline - Relative elongation at $10 \mathrm{MPa}$ load [\%] & $\frac{36 \pm 2}{25 \pm 3}$ & $\frac{34 \pm 2}{24 \pm 1}$ \\
\hline - Relative elongation before fracture [\%] & $\frac{67 \pm 4}{49 \pm 3}$ & $\frac{62 \pm 4}{45 \pm 3}$ \\
\hline - Yield $\left[\mathrm{m}^{2} /(100 \mathrm{~kg}\right.$ of raw hides $\left.)\right]$ & $15.1 \pm 0.3$ & $14.7 \pm 0.3$ \\
\hline
\end{tabular}

Note: The numerator and denominator correspond to the values for horsefront and shell, respectively, while * denotes that the mass fraction was recalculated on the dry basis. 


\section{Acknowledgments}

Authors thank Victor Marik and Olivia Lanier for participating in discussions and providing language help, writing assistance, and proofreading the paper and Creative Vector Studio (https:// www.etsy.com/shop/CreativeVectorStudio), particularly Tatiana Chernenko, for the help with graphical illustrations (illustration to Figure 1 and Figure 6).

\section{Funding}

This research did not receive any specific grants from funding agencies in the public, commercial, or not-for-profit sectors.

\section{References}

1. Cadirci, B. H.; Ozgunay, H.; Vural, C.; Yilmaz, O. A New Defect on Leather: Microbial Bio-Film. JALCA 105, 129-134, 2010.

2. Plutakhin, G. A.; Aider, M.; Koshchaev, A. G.; Gnatko, E. N. Theoretical Bases of Electrochemical Treatment of Aqueous Solutions (in Russian). Sci. J. Kuban State Agrar. Univ., 92 (08), 1-25, 2013.

3. Fidaleo, M.; Moresi, M. Electrodialysis Applications in the Food Industry. Adv. Food Nutr. Res. 51, 265-360, 2006. https://doi. org/10.1016/S1043-4526(06)51005-8.

4. Hsu, S.-Y.; Kao, H.-Y. Effects of Storage Conditions on Chemical and Physical Properties of Electrolyzed Oxidizing Water. J. Food Eng. 65 (3), 465-471, 2004. https://doi.org/10.1016/j.jfoodeng.2004.02.009.

5. Shirahata, S.; Hamasaki, T.; Teruya, K. Advanced Research on the Health Benefit of Reduced Water. Trends Food Sci. Technol. 23 (2), 124-131, 2012. https://doi.org/10.1016/j.tifs.2011.10.009.

6. Thorn, R. M. S.; Lee, S. W. H.; Robinson, G. M.; Greenman, J.; Reynolds, D. M. Electrochemically Activated Solutions: Evidence for Antimicrobial Efficacy and Applications in Healthcare Environments. European Journal of Clinical Microbiology and Infectious Diseases. Springer-Verlag, 641-653, May 2012. https:// doi.org/10.1007/s10096-011-1369-9.

7. Cloete, T. E.; Thantsha, M. S.; Maluleke, M. R.; Kirkpatrick, R. The Antimicrobial Mechanism of Electrochemically Activated Water against Pseudomonas Aeruginosa and Escherichia Coli as Determined by SDS-PAGE Analysis. J. Appl. Microbiol. 107(2), 379-384, 2009. https://doi.org/10.1111/j.1365-2672.2009.04233.x.

8. Wilsmann,D.E.; Carvalho, D.; Chitolina, G.Z.;Borges, K. A.; Furian, T. Q.; Martins, A. C.; Webber, B.; do Nascimento, V.P. ElectrochemicallyActivated Water Presents Bactericidal Effect against Salmonella Heidelberg Isolated from Poultry Origin. Foodborne Pathog. Dis., 1-6, 2019. https://doi.org/10.1089/fpd.2019.2682.

9. Goncharuk, V. V.; Bahryi, V. A.; Arkhypchuk, V. V.; Chebotarov, R. D. Biotesting of Electrochemically Activated Water (in Russian). J. Water Chem. Technol., 4, 399-411, 2005.

10. Marais, J. T.; Brözel, V. S. Electro-Chemically Activated Water in Dental Unit Water Line. Br. Dent. J., 187(3), 154-158, 1999. https:// doi.org/10.1038/sj.bdj.4800228.

11. Thorn, R. M. S.; Robinson, G. M.; Reynolds, D. M. Comparative Antimicrobial Activities of Aerosolized Sodium Hypochlorite,
Chlorine Dioxide, and Electrochemically Activated Solutions Evaluated Using a Novel Standardized Assay. Antimicrob. Agents Chemother., 57(5), 2216-2225, 2013. https://doi.org/10.1128/ AAC.02589-12.

12. Swan, J. S.; Deasy, E. C.; Boyle, M. A.; Russell, R. J.; O’Donnell, M. J.; Coleman, D. C. Elimination of Biofilm and Microbial Contamination Reservoirs in Hospital Washbasin U-Bends by Automated Cleaning and Disinfection with Electrochemically Activated Solutions. J. Hosp. Infect., 94(2), 169-174, 2016. https:// doi.org/10.1016/j.jhin.2016.07.007.

13. Akbulut, M. B.; Ünverdi Eldeniz, A. In Vitro Antimicrobial Activity of Different Electrochemicallyactivated Solutions on Enterococcus Faecalis. Eur. Oral Res. 53(1), 44-50, 2019. https://doi.org/10.26650/ eor.20194564125648.

14. Ghebremichael, K.; Muchelemba, E.; Petrusevski, B.; Amy, G. Electrochemically Activated Water as an Alternative to Chlorine for Decentralized Disinfection. J. Water Supply Res. Technol., AQUA, 60(4), 210-218, 2011. https://doi.org/10.2166/aqua.2011.034.

15. Gulabivala, K.; Stock, C. J. R.; Lewsey, J. D.; Ghori, S.; Ng, Y.-L.; Spratt, D. A. Effectiveness of Electrochemically Activated Water as an Irrigant in an Infected Tooth Model. Int. Endod. J., 37(9), 624631, 2004. https://doi.org/10.1111/j.1365-2591.2004.00867.x.

16. Pogorelov, A. G.; Suvorov, O. A.; Kuznetsov, A. L.; Panait, A. I.; Pogorelova, M. A.; Ipatova, L. G. Disintegration of Bacterial Film by Electrochemically Activated Water Solution. Bull. Exp. Biol. Med., 165(4), 493-496, 2018. https://doi.org/10.1007/s10517-018-4202-y.

17. Solovyeva, A. M.; Dummer, P. M. H. Cleaning Effectiveness of Root Canal Irrigation with Electrochemically Activated Anolyte and Catholyte Solutions: A Pilot Study. Int. Endod. J., 33(6), 494504, 2000. https://doi.org/10.1046/j.1365-2591.2000.00342.x.

18. Cronjé, N.; Steyn, H. J. H.; Schall, R. Catholyte as an Environmentally Friendly Detergent: Effect on the Colourfastness of Black Dyed Textiles. J. Text. Inst. 2019. https://doi.org/10.1080/0 0405000.2019.1703489.

19. Pogorelova, M. A.; Kuznetsov, A. L.; Suvorov, O. A. Does Electrochemically Reduced Water Remove Bacterial Film? Int. J. Pharm. Res. Allied Sci., 7(2), 139-142, 2018.

20. Rogers, J. V.; Ducatte, G. R.; Choi, Y. W.; Early, P. C. A Preliminary Assessment of Bacillus Anthracis Spore Inactivation Using an Electrochemically Activated Solution (ECASOL ${ }^{\mathrm{TM}}$ ). Lett. Appl. Microbiol., 43(5), 482-488, 2006. https://doi.org/10.1111/j.1472765X.2006.02002.x.

21. Robinson, G. M.; Lee, S. W.-H.; Greenman, J.; Salisbury, V. C.; Reynolds, D. M. Evaluation of the Efficacy of Electrochemically Activated Solutions against Nosocomial Pathogens and Bacterial Endospores. Lett. Appl. Microbiol., 50(3), 289-294, 2010. https:// doi.org/10.1111/j.1472-765X.2009.02790.x.

22. Robinson, G.; Thorn, R.; Reynolds, D. The Effect of Long-Term Storage on the Physiochemical and Bactericidal Properties of Electrochemically Activated Solutions. Int. J. Mol. Sci., 14(1), 457469, 2013. https://doi.org/10.3390/ijms14010457.

23. Michel, N. S. D.; Paletta, J. R. J.; Kerwart, M.; Skwara, A. Role of Electrochemically Activated Solution in Asepsis in Osteoblasts and Chondrocytes in Vitro. J. Investig. Surg., 29(3), 157-166, 2016. https://doi.org/10.3109/08941939.2015.1098757. 
24. Lee, M. Y.; Kim, Y. K.; Ryoo, K. K.; Lee, Y. B.; Park, E. J. ElectrolyzedReduced Water Protects against Oxidative Damage to DNA, RNA, and Protein. Appl. Biochem. Biotechnol., 135(2), 133-144, 2006. https://doi.org/10.1385/ABAB:135:2:133.

25. Kinjo, T.; Ye, J.; Yan, H.; Hamasaki, T.; Nakanishi, H.; Toh, K.; Nakamichi, N.; Kabayama, S.; Teruya, K.; Shirahata, S. Suppressive Effects of Electrochemically Reduced Water on Matrix Metalloproteinase-2 Activities and in Vitro Invasion of Human Fibrosarcoma HT1080 Cells. In Cytotechnology; Springer Netherlands, 64, 357-371, 2012. https://doi.org/10.1007/s10616-012-9469-7.

26. Yang, Z.; Li, Y.; Slavik, M. F. Antibacterial Efficacy of Electrochemically Activated Solution for Poultry Spraying and Chilling. J. Food Sci., 64(3), 469-472, 1999. https://doi. org/10.1111/j.1365-2621.1999.tb15065.x.

27. Thorn, R. M. S.; Pendred, J.; Reynolds, D. M. Assessing the Antimicrobial Potential of Aerosolised Electrochemically Activated Solutions (ECAS) for Reducing the Microbial Bio-Burden on Fresh Food Produce Held under Cooled or Cold Storage Conditions. Food Microbiol., 68, 41-50, 2017. https://doi.org/10.1016/j.fm.2017.06.018.

28. Surdu, I.; Vătuiu, D.; Jurcoane, Ş.; Olteanu, M.; Vătuiu, I. The Antimicrobial Activity of Neutral Electrolyzed Water against Germs and Fungi from Feedstuffs, Eggshells and Laying Hen House. Rom. Biotechnol. Lett., 23(3), 2018.

29. Lutsyk, R. V.; Matvienko, O. A.; Bovsunovskyi, O. V. Possibilities of Using Electroactivated Water in Technological Processes for Shoe Production (in Ukrainian). Bull. Kyiv Natl. Univ. Technol. Des., 2, 53-58, 2005.

30. Zorina, E. F.; Zeleva, G. M.; Nagornaia, Z. E. The Effect of the Nature of Tanning Agents and Water on the Plastic Properties of the Skin Tissues of Fur and Leather (in Russian). J. Omsk Sci. Bull., 19, 140-141, 2002.

31. Zorina, E. F.; Zeleva, G. M. Dyeing of Fur with Various Dyes (in Russian). J. Omsk Sci. Bull., 19, 138-139, 2002.

32. Danylkovych, A. G.; Lishchuk, V. I.; Romaniuk, O. O. Use of Electrochemically Activated Aqueous Solutions in the Manufacture of Fur Materials. Springerplus, 5(1), 1-11, 2016. https://doi.org/10.1186/s40064-016-1784-6.

33. Danylkovych, A. H.; Mokrynska, O. R.; Okhmat, O. A. Technology and Materials for Leather Production (in Ukrainian); Danylkovych, A. H., Ed.; Phoenix: Kyiv, 2009.

34. Basil-Jones, M. M.; Edmonds, R. L.; Cooper, S. M.; Kirby, N.; Hawley, A.; Haverkamp, R. G. Collagen Fibril Orientation and Tear Strength across Ovine Skins. J. Agric. Food Chem., 61(50), 1232712332, 2013. https://doi.org/10.1021/jf4038375.

35. Apukhovskyi, A. Y.; Krutov, V. D.; Kosinov, B. V. Process for Producing Drinking and Medicinal Water. 49551, 2002.

36. Potapenko, S. I.; Kostiuk, O. M.; Kostiuk, I. O.; Marinchenko, V. O. Mechanism for Preparing Silicon Potable Water. 19633, 2006.

37. Danylkovych, A. H.; Chursyn, B. I. Technological Methodology for Production of Variety of Leather Materials for Upper Shoe Parts and Shoe Lining, Leather Haberdashery from Cattle and Horse Hides (in Ukrainian); JSC Chinbar: Kyiv, 2003.

38. Danylkovych, A. H.; Korotych, O. I. Optimization of Leather Filling Composition Containing $\mathrm{SiO}_{2}$ Nanoparticles. JALCA 114, 333-343, 2019.

39. Danylkovych, A. H.; Chursyn, V. I. Analytical Control in Leather and Fur Production: A Laboratory Practicum (in Russian); Infra-M: Moscow, 2016
40. Zhang, Y.; Mansel, B. W.; Naffa, R.; Cheong, S.; Yao, Y.; Holmes, G.; Chen, H.-L.; Prabakar, S. Revealing Molecular Level Indicators of Collagen Stability: Minimizing Chrome Usage in Leather Processing. ACS Sustain. Chem. Eng., 6(5), 7096-7104, 2018. https://doi.org/10.1021/acssuschemeng.8b00954.

41. Alberts, B.; Bray, D.; Hopkin, K.; Johnson, A.; Lewis, J.; Raff, M.; Roberts, K.; Walter, P. Essential Cell Biology, Fourth.; Garland Science (Taylor \& Francis Group): New York, 2013.

42. Covington, A. D. Modern Tanning Chemistry. Chem. Soc. Rev., 26(2), 111-126, 1997. https://doi.org/10.1039/cs9972600111.

43. Brown, E. M. Collagen - a Natural Scaffold for Biology and Engineering. JALCA 104, 275-285, 2009.

44. Sizeland, K. H.; Edmonds, R. L.; Basil-Jones, M. M.; Kirby, N.; Hawley, A.; Mudie, S.; Haverkamp, R. G. Changes to Collagen Structure during Leather Processing. J. Agric. Food Chem., 63(9), 2499-2505, 2015. https://doi.org/10.1021/jf506357j.

45. Buchanan, J. K.; Zhang, Y.; Holmes, G.; Covington, A. D.; Prabakar, S. Role of X-ray Scattering Techniques in Understanding the Collagen Structure of Leather. ChemistrySelect, 4(48), 1409114102, 2019. https://doi.org/10.1002/slct.201902908.

46. Naffa, R.; Maidment, C.; Ahn, M.; Ingham, B.; Hinkley, S.; Norris, G. Molecular and Structural Insights into Skin Collagen Reveals Several Factors That Influence Its Architecture. Int. J. Biol. Macromol., 128, 509-520, 2019. https://doi.org/10.1016/j.ijbiomac.2019.01.151.

47. Zhang, Y.; Ingham, B.; Cheong, S.; Ariotti, N.; Tilley, R. D.; Naffa, R.; Holmes, G.; Clarke, D. J.; Prabakar, S. Real-Time Synchrotron Small-Angle X-Ray Scattering Studies of Collagen Structure during Leather Processing. Ind. Eng. Chem. Res., 57(1), 63-69, 2018. https://doi.org/10.1021/acs.iecr.7b03860.

48. Bowes, J. H.; Kenten, R. H. The Swelling of Collagen in Alkaline Solutions. 1. Swelling in Solutions of Sodium Hydroxide. Biochem. J., 46(1), 1-8, 1950. https://doi.org/10.1042/bj0460001.

49. Highberger, J. H. The Isoelectric Point of Collagen. JALCA 61(9), 2302-2303, 1939. https://doi.org/10.1021/ja01878a010.

50. Knaggs, J. Studies on Collagen. The Changes Which Collagen Undergoes When Treated with Solutions of Hydrochloric Acid and Sodium Hydroxide1. Biochem. J., 23(6), 1308-1327,1929. https:// doi.org/10.1042/bj0231308.

51. Samchenko, Y.; Ulberg, Z.; Korotych, O. Multipurpose Smart Hydrogel Systems. Adv. Colloid Interface Sci., 168(1-2), 247-262, 2011. https://doi.org/10.1016/j.cis.2011.06.005.

52. Basford, J. The Soaking, Unhairing and Liming Process: Part 1 of 3 . The Practicalities of the Soaking Process. World Leather, 19(7), 23-26, 2006.

53. Fratzl, P. Collagen: Structure and Mechanics, an Introduction. In Collagen: Structure and Mechanics; Springer US,1-13, 2008. https:// doi.org/10.1007/978-0-387-73906-9_1.

54. Miles, C. A.; Avery, N. C.; Rodin, V. V.; Bailey, A. J. The Increase in Denaturation Temperature Following Cross-Linking of Collagen Is Caused by Dehydration of the Fibres. J. Mol. Biol., 346(2), 551556, 2005. https://doi.org/10.1016/j.jmb.2004.12.001.

55. Witnauer, L. P.; Fee, J. G. Effect of Diluents on Fusion Temperature of the Crystalline Regions in Plain and Tanned Cowhide. J. Polym. Sci., 26(113), 141-150,1957. https://doi.org/10.1002/pol.1957.1202611302.

56. Flory, P. J.; Garrett, R. R. Phase Transitions in Collagen and Gelatin Systems. J. Am. Chem. Soc., 80 (18), 4836-4845, 1958. https://doi. org/10.1021/ja01551a020. 